\title{
Design and Implementation of an Automatic Voltage Regulator with a Great Precision and Proper Hysteresis
}

\author{
Mohammad Shah Alamgir ${ }^{1}$ and Sumit Dev ${ }^{2}$ \\ Department of Applied Physics, Electronics and Communication Engineering, \\ University of Chittagong \\ Chittagong-4331, Bangladesh \\ ${ }^{1}$ shah_a@cu.ac.bd
}

\begin{abstract}
This research aims at the designing and implementation of an Automatic Voltage Regulator (AVR) with higher precision and hysteresis. AC power supplied by PDB (Power development board) in Bangladesh is subjected to variation from time to time. Moreover in rural areas supplied voltage remains lower than specified. This causes a considerable threat to the sophisticated electronic devices like computer, refrigerator, television etc. So ensuring the input voltage to remain in a tolerable pre-specified limit has become a necessity in rural as well as some urban areas. Current systems available locally lacks precision and suffers the problem of oscillating between two output voltage and hence creating surge at the output which can damage valuable electronics. This research handled both shortcomings and introduced in the tolerable range of 215-237 volt using several taps. Hysteresis has been introduced while changing from one level to other and thus preventing oscillation.
\end{abstract}

Keywords: Automatic Voltage Regulator (AVR), precision, hysteresis, auto transformer, comparator circuit, relay, PDB (Power development board)

\section{Introduction}

In our practical life voltage may be high or low for purpose of electricity supply system or for the weakness of supply system or for other causes. For that reason, many important electric machine or electric equipment may destroy. In order to save these we need to use the voltage regulator.

The voltage regulator may be manually or automatically controlled. The voltage can be regulated manually by tap-changing switches, a variable auto transformer, and an induction regulator [1]. In manual control, the output voltage is sensed with a voltmeter connected at the output; the decision and correcting operation is made by a human being [2]. The manual control may not always be feasible due to various factors and the accuracy, which can be obtained, depending on the degree of instrument and giving much better performance so far as stability [2]. In modern large interconnected system, manual regulation is not feasible and therefore automatic voltage regulation equipment is installed on each generator [1].

Power quality problems commonly faced by industrial operations include transients, sags, swells, surges, outages, harmonics, and impulses that vary in quantity or magnitude of the voltage [3, 4]. Of these, voltage sags and extended under voltages have the largest negative impact on industrial productivity, and could be the most significant type of power quality variation for many industrial and commercial customers [3-9]. AVR is a suitable choice to control the output voltage through field excitation in variable speed application [10]. 


\section{Specifications}

Based on the above initial design decisions, the final parameters/specifications:
- Input voltage: $150 \mathrm{~V}$ to $273 \mathrm{~V}$

- Output voltage: $215 \mathrm{~V}$ to $237 \mathrm{~V}$ for all input lying between $150 \mathrm{~V}$ and $273 \mathrm{~V}$

- Input and output frequency are the same

- High cut feature at $274 \mathrm{~V}$

- Low cut feature at $145 \mathrm{~V}$

- 8 relays are used

- The auto-transformer has a $0 \mathrm{~V} /$ neutral connection and 8 additional tapping's : $315 \mathrm{~V}, 285 \mathrm{~V}$, $257 \mathrm{~V}, 233 \mathrm{~V}, 212 \mathrm{~V}, 190 \mathrm{~V}, 172 \mathrm{~V}$, $156 \mathrm{~V}$

\section{Related Work}

In existing market, a traditional voltage regulator $[11,12,14]$ normally designed is only suitable at synchronous speed of the primer mover [10] and it may cause easy burn out of the power electronic components if hunting and speed change occurs.

In the earlier research, 100V-340V (PAVR) [13], 120V-350V (AVR) [14] regulates the actual input voltage variation with an imprecise output voltage and improper hysteresis.

\section{Overview of the Proposed Design}

By the following block diagram the whole system can be recognized easily.

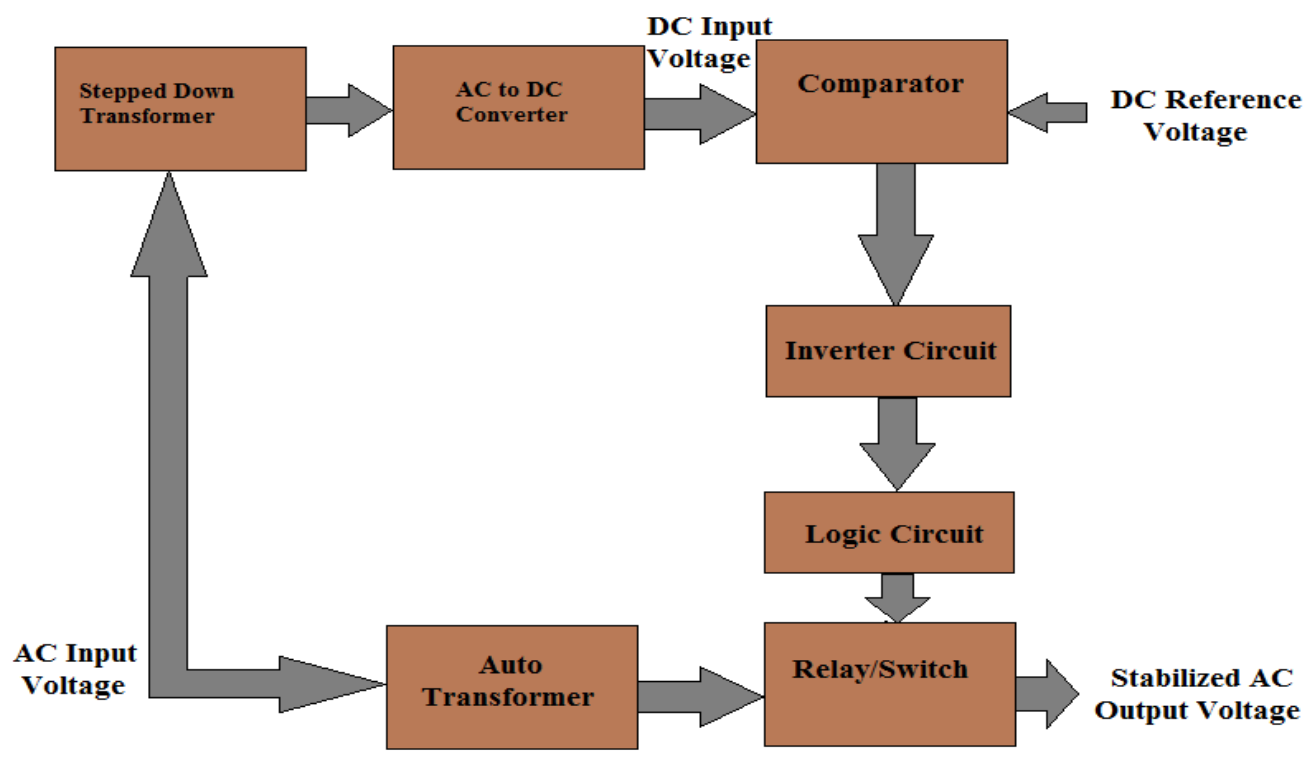

Figure 1. Block Diagram of the AVR Design

Input supply and switches connected with a multi-tapped transformer in primary and in secondary respectively to obtain regulated and stabilized output voltage at the load side is used [13]. Here comparator circuit plays the important role to decide and hence to control 
the switches through which secondary tap carries the power from input to load with a steady voltage.

It is necessary to introduce two units, one to prevent hunting known as anti-hunting unit and another to maintain hysteresis known as hysteresis circuit [14, 15, 16-18]. Hunting is continuous fluctuation or oscillation of the voltage regulator and hysteresis is a change of the voltage from the one comparator to another and vice-versa [14]. The poor hysteresis means the less difference of the input voltages while changing the comparator stages [14].

\section{Circuit Description}

\section{A. 12 volt Power Supply}

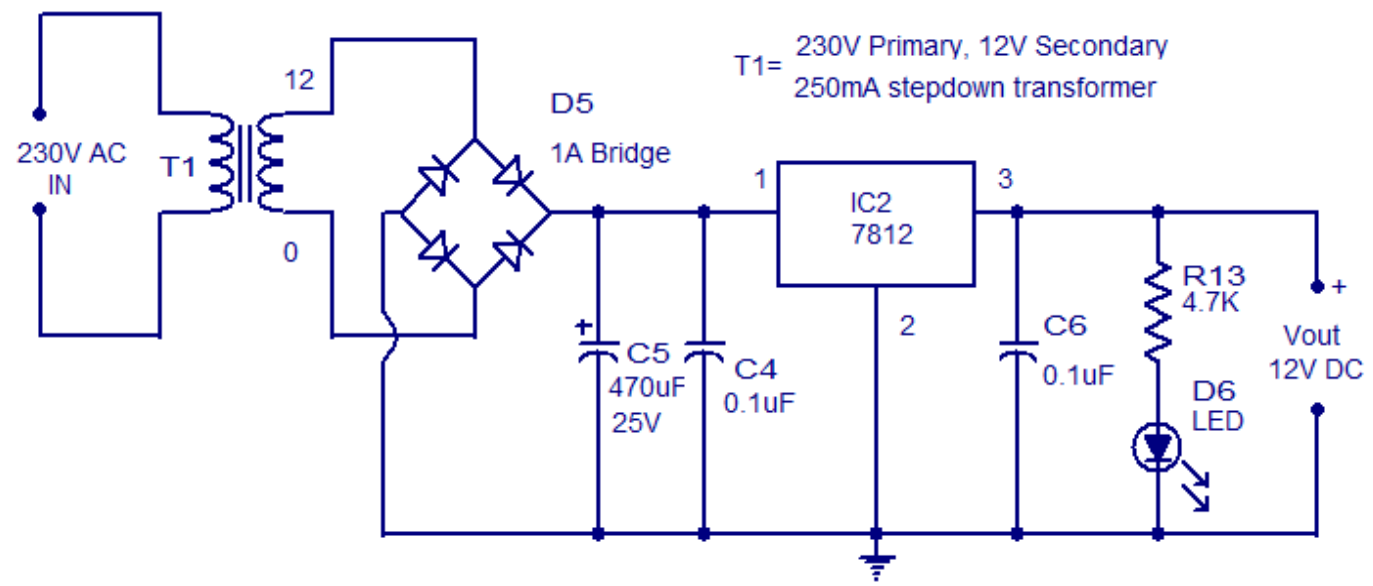

Figure 2. 12 volt Power Supply

This circuit is design for getting 12 volt dc stable power supply; here we use IC 7812 which give the fixed $12 \mathrm{v} \mathrm{dc}$. It is use as reference voltage of comparator circuit and for the biasing of LM324.

\section{B. 5 volt Power Supply}

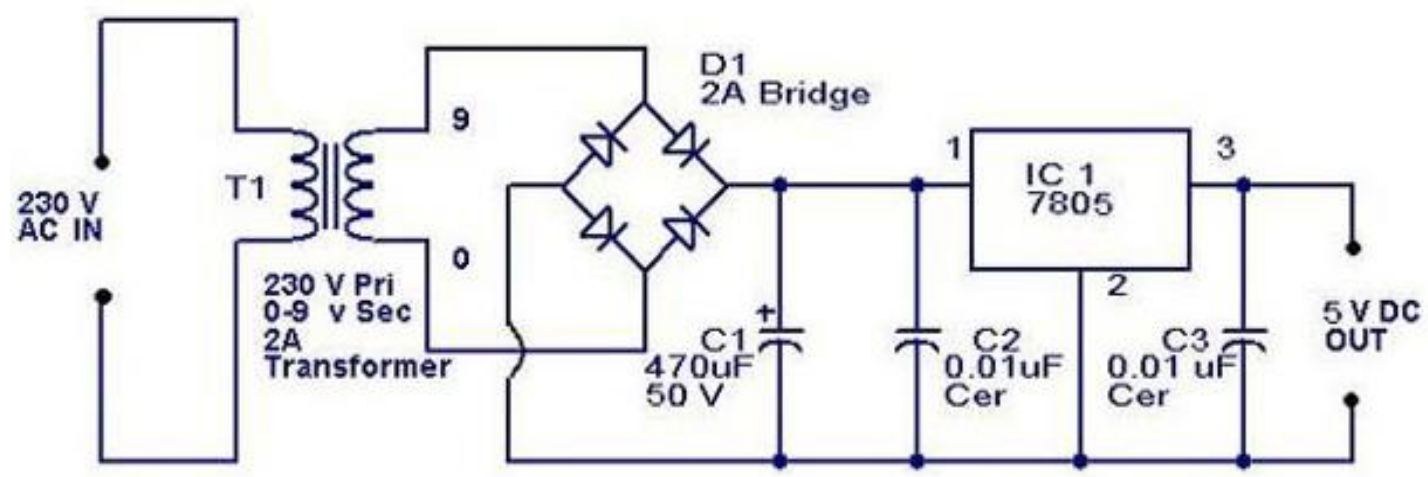

Figure 3. 5 volt Power Supply

This circuit is design for getting 5 volt dc stable power supply; here we use IC 7805 which give the fixed $5 \mathrm{v}$ dc. It is use to drive the inverter circuit and logic circuit. 


\section{Input Voltage Circuit}

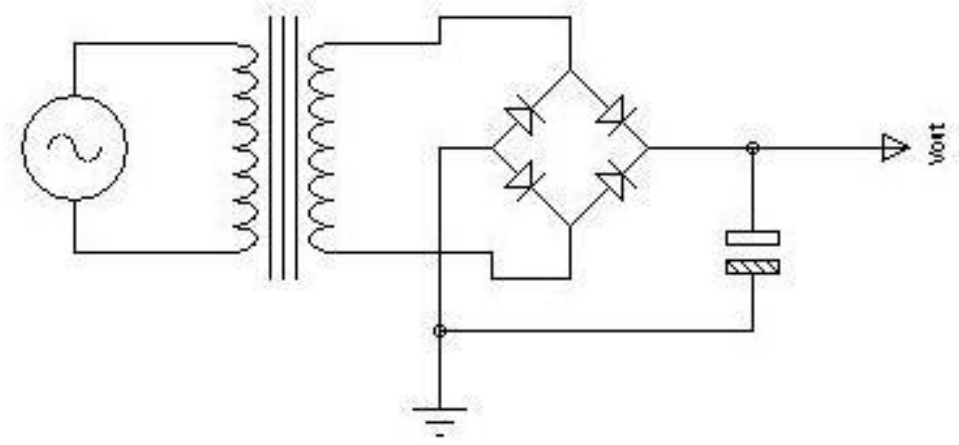

Figure 4. Input Voltage Circuit

The input voltage is generated by a step down transformer is feed to inverting terminal of the op-amp as Vin.

\section{Comparator Circuit}

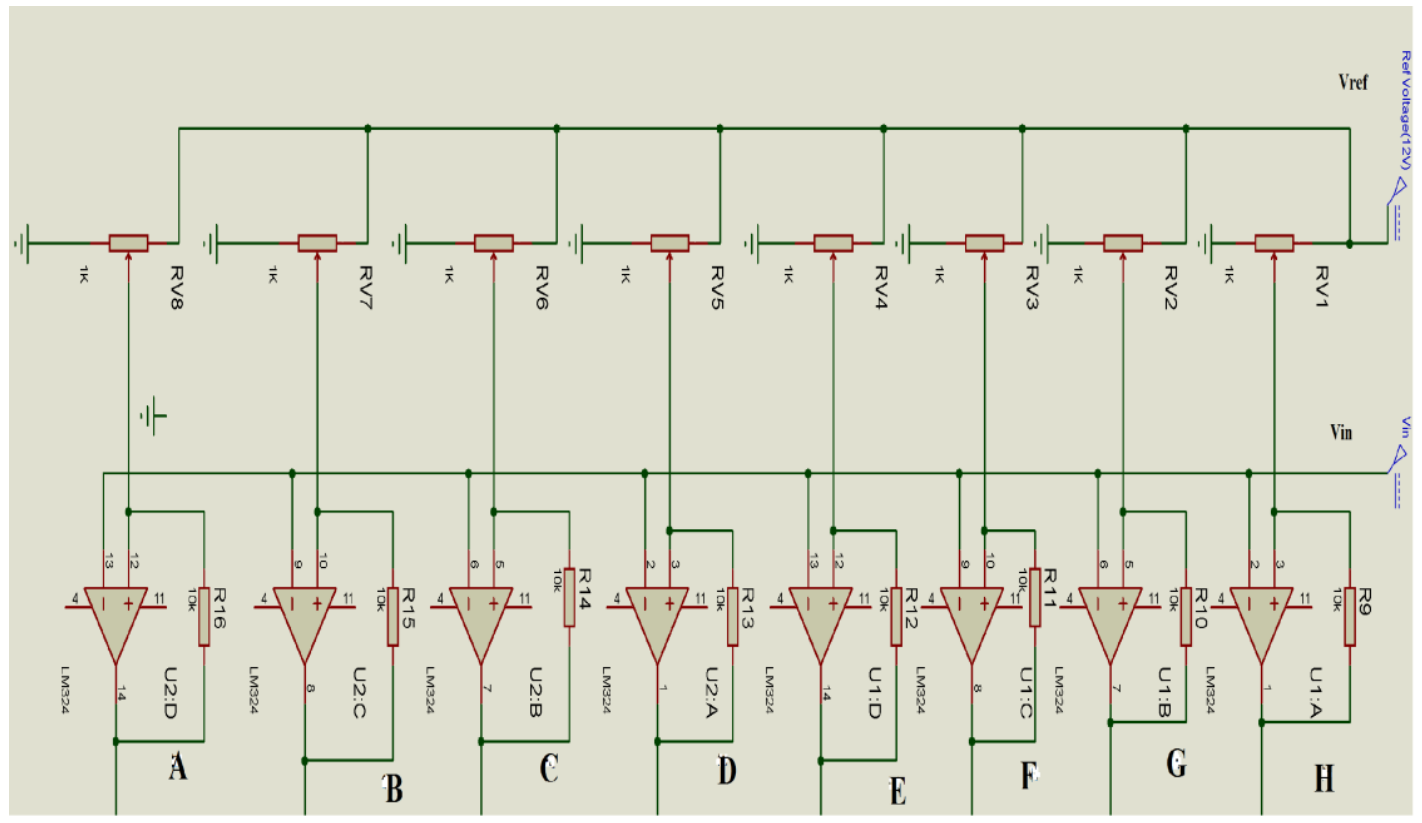

Figure 5. Comparator Circuit

LM324 are use for the comparator circuit which compares a variable dc voltage which is found by step down voltage (220vac-12vdc) of the PDB supply voltage with the reference voltage $(12 \mathrm{v} \mathrm{dc})$.

The reference voltage is chosen in different manner to the comparators to compare the variable input voltage for energizing the relays.

For a typical example comparators' input voltage combinations are shown in the following table: 
Table 1. Comparator Selection

\begin{tabular}{|c|c|c|c|}
\hline Input $\mathbf{V}_{\mathbf{A C}}$ (volt) & $\mathbf{V}_{\text {ref }}$ (Volt DC) & $\mathbf{V}_{\text {in }}$ (volt DC) & Output of Comparator \\
\hline $\mathbf{1 4 5}$ & $\mathbf{3 . 6 0}$ & $\mathbf{3 . 7 1}$ & $\mathbf{A}$ \\
\hline 150 & 3.75 & 3.83 & $\mathrm{~B}$ \\
\hline 166 & 4.10 & 4.24 & $\mathrm{C}$ \\
\hline 184 & 4.50 & 4.70 & $\mathrm{D}$ \\
\hline 203 & 4.90 & 5.19 & $\mathrm{E}$ \\
\hline 224 & 5.55 & 5.73 & $\mathrm{~F}$ \\
\hline 248 & 6.10 & 6.34 & $\mathrm{G}$ \\
\hline 274 & 6.85 & 7.01 & $\mathrm{H}$ \\
\hline
\end{tabular}

Here, Input $\mathrm{V}_{\mathrm{AC}}($ volt) defines input voltage for $\mathrm{AVR}$

$\mathrm{V}_{\text {ref }}($ Volt DC) defines non-inverting input for comparator

$\mathrm{V}_{\text {in }}$ (volt DC) defines inverting input for comparator

\section{E. Inverter Circuit}

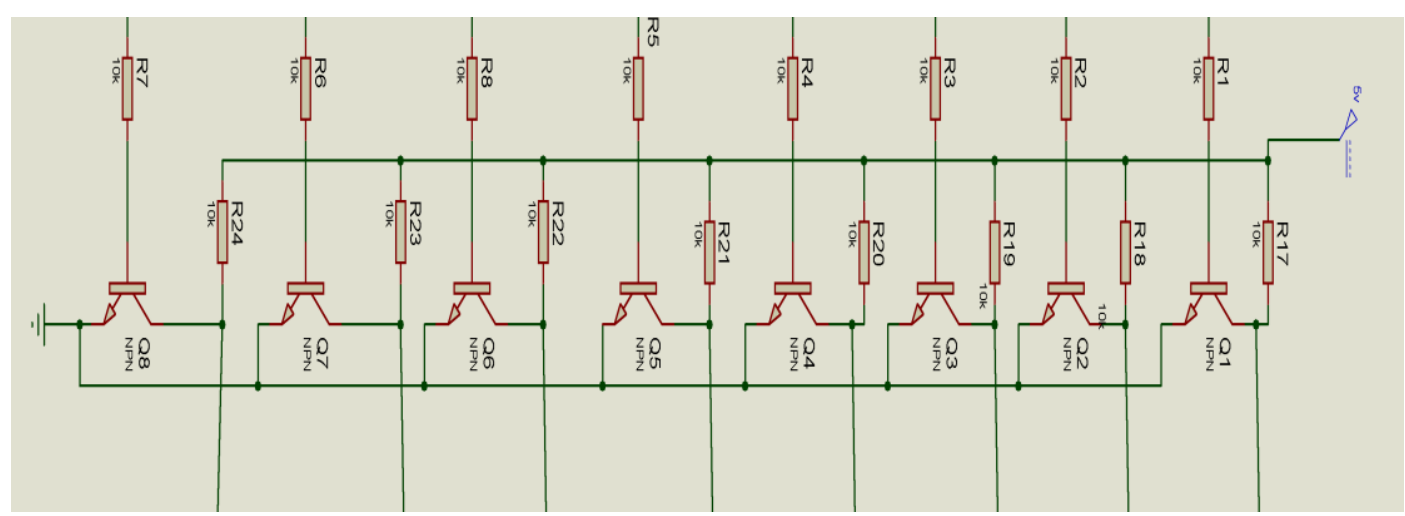

Figure 6. Inverter Circuit

The output of the comparator circuit is connected to the base of the transistor. When Vin is less than Vref then output is zero \& when Vin is greater than Vref then output from collector is $5 \mathrm{~V}$.

\section{F. Logic Circuit}

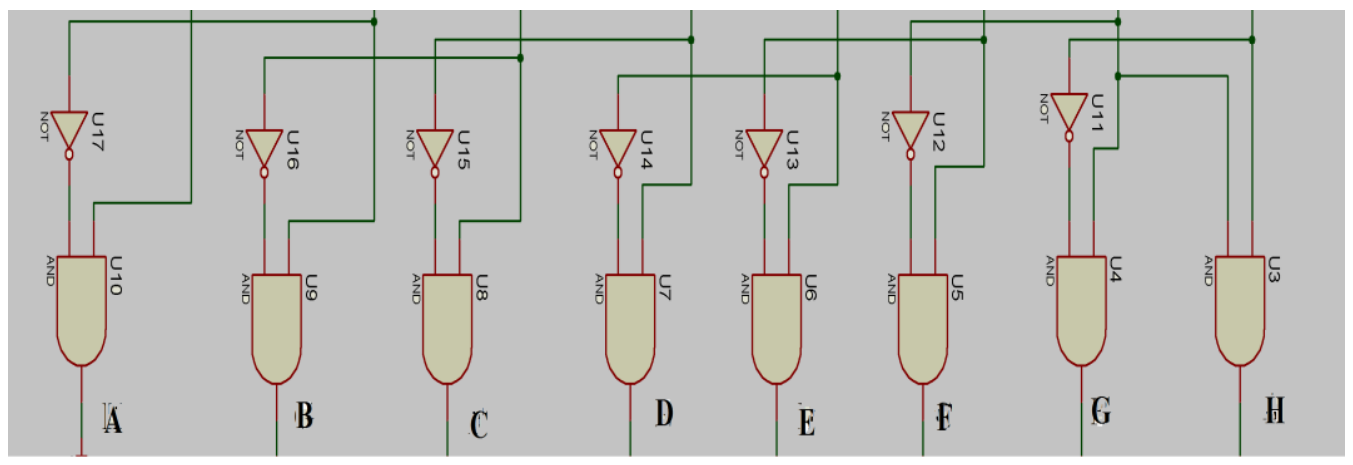

Figure 7. Logic Circuit 
The output of the inverter circuit is feed to the logic circuit which acts as a decoder. We find the output of the logic circuit by the following truth table:

Table 2. Relay Selection

\begin{tabular}{|l|l|l|l|l|l|l|l|l|l|}
\hline A & B & C & D & E & F & G & H & O/P & Relay \\
\hline 0 & 0 & 0 & 0 & 0 & 0 & 0 & 0 & OFF & 0 \\
\hline 1 & 0 & 0 & 0 & 0 & 0 & 0 & 0 & A $\underline{B}$ & R1 \\
\hline 1 & 1 & 0 & 0 & 0 & 0 & 0 & 0 & B $\underline{\mathrm{C}}$ & R2 \\
\hline 1 & 1 & 1 & 0 & 0 & 0 & 0 & 0 & C $\underline{D}$ & R3 \\
\hline 1 & 1 & 1 & 1 & 0 & 0 & 0 & 0 & DE & R4 \\
\hline 1 & 1 & 1 & 1 & 1 & 0 & 0 & 0 & EF & R5 \\
\hline 1 & 1 & 1 & 1 & 1 & 1 & 0 & 0 & FG & R6 \\
\hline 1 & 1 & 1 & 1 & 1 & 1 & 1 & 0 & G $\underline{H}$ & R7 \\
\hline 1 & 1 & 1 & 1 & 1 & 1 & 1 & 1 & GH & R8 \\
\hline
\end{tabular}

\section{G. Relay Driver Circuit}

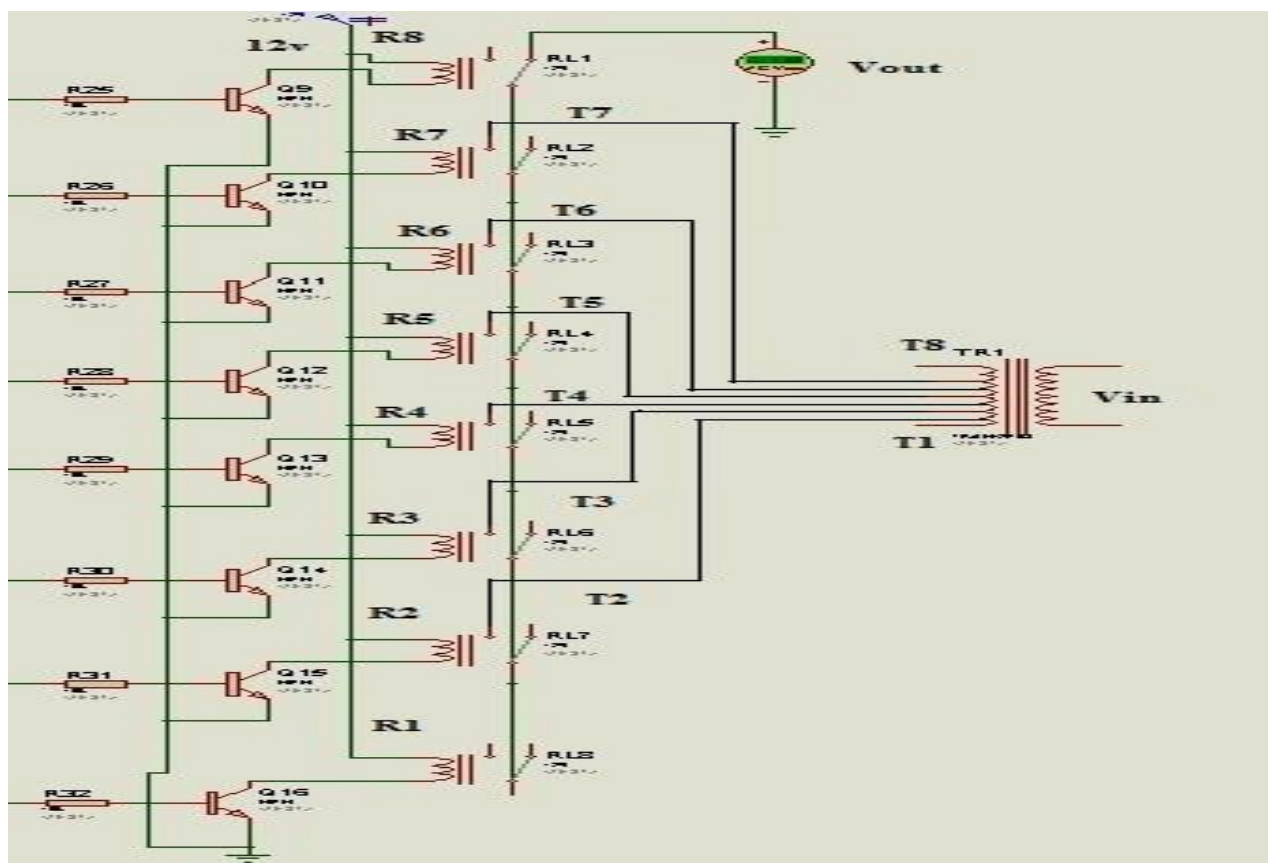

Figure 8. Relay Driver Circuit

Output of the logic circuit select relays for getting stable output voltage. The transformer is a simple autotransformer with the turn ratio $315 \mathrm{~V}: 285 \mathrm{~V}: 257 \mathrm{~V}: 233 \mathrm{~V}$ : 212V: 190V: 172V: 156V along with an auxiliary winding for powering the circuitry.

\section{Procedure towards Design}

As our designing commitment which is to stabilize automatically a large range (150V$273 \mathrm{~V}$ ) variation of input voltage at a normal prescribed level output voltage with a great precision and proper hysteresis. For this the voltage regulation of input supply is designed which is regulated automatically in such a way that when the input voltage varies the output voltage will remain stable at a constant level $[14,15,19,20]$. To attain the variation of the large range input voltage, a mechanism is defined to stabilize a large 
range i.e., $150 \mathrm{~V}-273 \mathrm{~V}$ of the input by using the measuring circuit which drives multitapped transformer to select the appropriate tap $[14,20]$ and also the way that is inserted to make the system for the precision of output, is the selection of a transformer of a many number of taps in the secondary winding side maintaining a small turn difference between two successive taps $[14,20]$. To maintain a good hysteresis a feedback is formed in the comparator circuit with a variable resistance $[14,16,21]$. Here the variable resistance provides a differential value to the input of comparator during the changing of the comparator stages and also adjusts the hysteresis condition.

In this design a transformer of eight taps has been chosen from lowest tap to highest i.e., T2, T3, T4, T5, T6, and $\mathrm{T} 7$ in the secondary side those are selected by the relays/switches R2, R3, R4, R5, R6, and R7 respectively. Here the relays are controlled by a measuring unit consisting of comparators $[14,16,21]$ (A, B, C, D, E, F, G, and H) The comparator compares a dc input with a reference level where the dc input voltage varies in accordance with the variation of supply input voltage and it selects the appropriate tap. Hence the stable output is found from the secondary side of transformer. This design is depicted in the following practical circuit diagram (Figure 9).

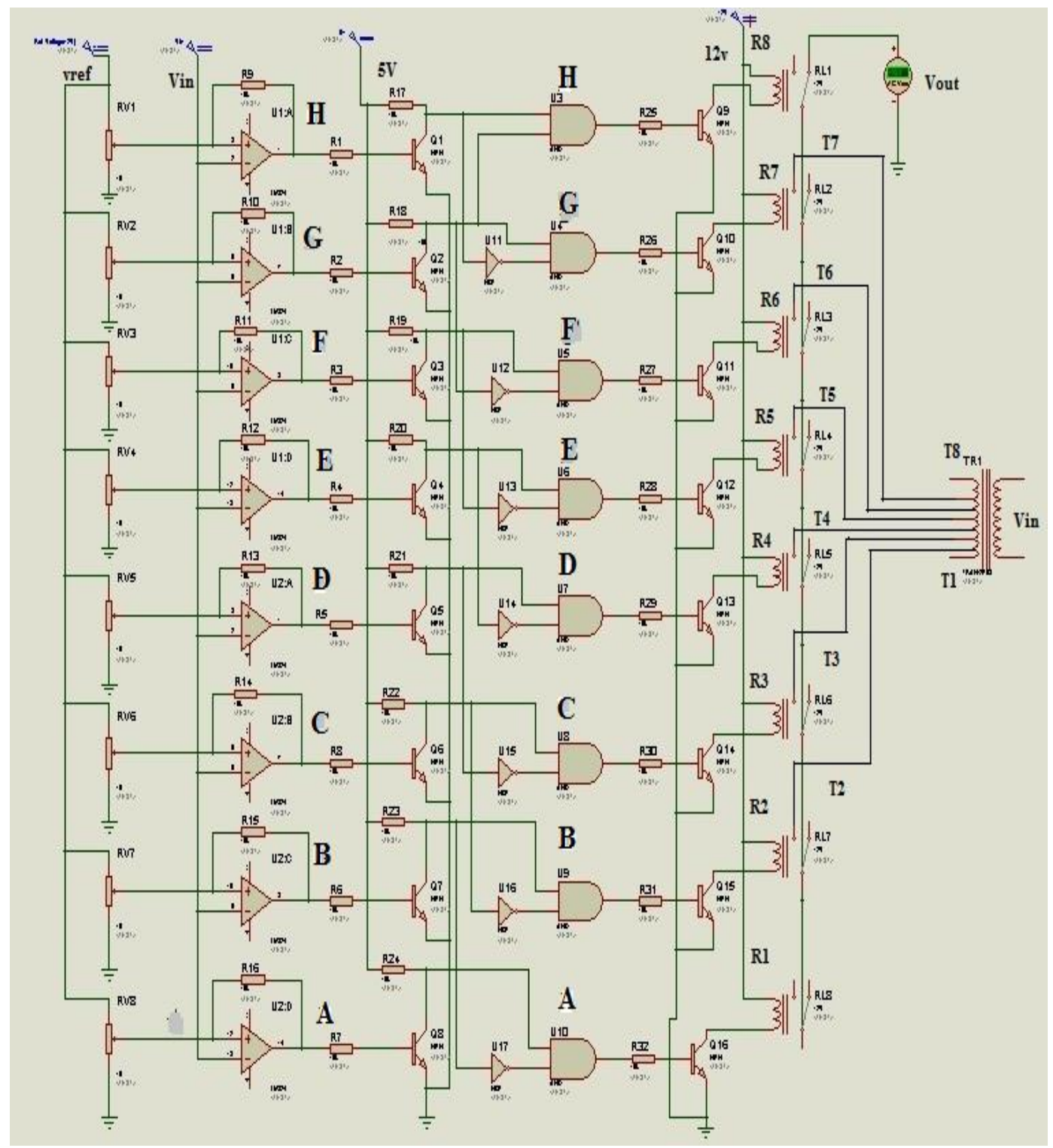

Figure 9. Practical Circuit Diagram 
The stable output voltage occurs in the output of our designed regulated system for any short of variation of input voltage automatically. It is cleared to us from the following table:

Table 3. Transformer Tap Selection

\begin{tabular}{|c|c|c|c|c|}
\hline $\begin{array}{c}\text { Input } \\
\text { (volt) }\end{array}$ & $\begin{array}{c}\text { Voltage for } \\
\text { Tap Selection }\end{array}$ & Tap no. & $\begin{array}{c}\text { Switch } \\
\text { Selection }\end{array}$ & $\begin{array}{c}\text { Stabilized Output } \\
\text { Voltage }\end{array}$ \\
\hline 145 & -- & -- & R1 & 0 V \\
\hline 150 & 315 & T2 & R2 & $214.77 \approx 215$ \\
\hline 166 & 285 & T3 & R3 & 215.0 \\
\hline 184 & 257 & T4 & R4 & $214.94 \approx 215$ \\
\hline 203 & 233 & T5 & R5 & $214.99 \approx 215$ \\
\hline 224 & 212 & T6 & R6 & $215.85 \approx 215$ \\
\hline 248 & 190 & T7 & R7 & $214.18 \approx 215$ \\
\hline 274 & -- & -- & R8 & $0 \mathrm{~V}$ \\
\hline
\end{tabular}

\section{Shortcomings Recovery}

The main goal of our research is to recovery of the shortcomings of the existing automatic voltage regulating system. In this portion these are described by the followings:

\subsection{To get the Stabilized Output for a Large Variation of Input Voltage}

Automatic voltage regulator has an enormous uses in human daily life where it is able to regulate a small range variation of input voltage that makes an obstacle of human life from the power because of not stabilizing the low and high voltage values. To recover that situation our research defines the mechanism to stabilize a large range of input voltage from lowest value to highest value by considering such measuring circuit which drives transformer of multiple times step up secondary side from the primary side.

\subsection{To get the Precision Output}

The commercially available automatic voltage regulator has a three to four step stabilization of the input variable voltage where the output becomes a big changing stable value within a prescribed range that is not an absolute design to get an output précised. For this reason in our research the way has been adopt to make the system for getting the precision output within in a large variation of input is the design of the main transformer having a many number of taps in the secondary winding side of the transformer maintaining a small turn difference between two adjacent taps.

\subsection{To get a Regulated Output with a Proper Hysteresis}

Hysteresis can be defined in such a way that a change in the value of the voltage when it reaches the level for the upper comparator and back to the previous position. The poor value of hysteresis means the less difference of the voltage values for changing and backing from the comparator stage. It is the general problem in our daily used AVR that causes a rapid alternation in the switching. In our research this problem is removed by employing a technique to maintain a good hysteresis which is a feedback connection in the comparator from output to inverting input with a variable resistance that shown in below. 


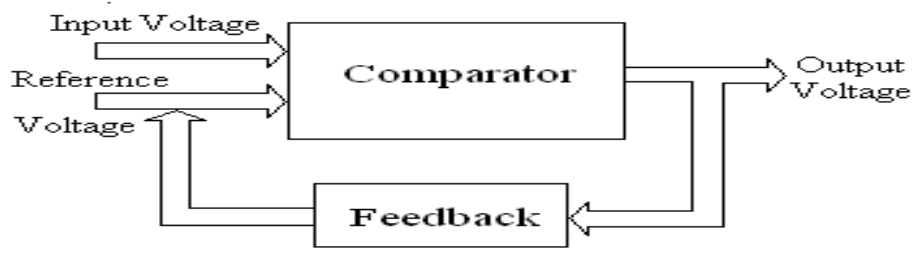

Figure 10. Hysteresis Circuit

Here the variable resistance provides a differential value of voltages during the changing and backing from the comparator stage and also adjusts the hysteresis condition.

\section{Performance Analysis}

We implemented this design practically for getting a clear performance after the completion of the design. We affirm with proof that the AVR turned on and stabilized any variable input voltage within our prescribed range $(150 \mathrm{~V} \sim 273 \mathrm{~V})$ to the tolerable range of 215-237 volt AC output which is in the following table:

Table 4. AVR Output without Hysteresis and Due to Hysteresis

\begin{tabular}{|c|c|c|c|c|c|c|}
\hline $\begin{array}{c}\text { AVR } \\
\text { INPUT }\end{array}$ & RATIO & AVR OUTPUT & $\begin{array}{c}\text { AVR } \\
\text { INPUT }\end{array}$ & RATIO & $\begin{array}{c}\text { AVR OUTPUT DUE TO } \\
\text { HYSTERESIS }\end{array}$ & Relay \\
\hline $150 \sim 165$ & 1.4334 & $215.01(\approx 215) \sim 236.511(\approx 237)$ & $146 \sim 161$ & 1.4334 & $209.2764 \sim 230.7774$ & R2 \\
\hline $166 \sim 183$ & 1.2952 & $215.0032(\approx 215) \sim 237.0216(\approx 237)$ & $162 \sim 178$ & 1.2952 & $209.8224 \sim 230.5456$ & R3 \\
\hline $184 \sim 202$ & 1.1685 & $215.004(\approx 215) \sim 236.037(\approx 237)$ & $179 \sim 197$ & 1.1685 & $209.1615 \sim 230.1945$ & $R 4$ \\
\hline $203 \sim 223$ & 1.0592 & $215.0176(\approx 215) \sim 236.2016(\approx 237)$ & $198 \sim 217$ & 1.0592 & $209.7216 \sim 229.8464$ & $R 5$ \\
\hline $224 \sim 247$ & 0.9599 & $215.0176(\approx 215) \sim 237.0953(\approx 237)$ & $218 \sim 241$ & 0.9599 & $209.2582 \sim 231.3359$ & $R 6$ \\
\hline $248 \sim 273$ & 0.867 & $215.016(\approx 215) \sim 236.691(\approx 237)$ & $242 \sim 273$ & 0.867 & $209.814 \sim 236.691$ & $R 7$ \\
\hline
\end{tabular}

Here it is cleared to us that the output voltage within a stable range from our design has been found for any input voltage variation with a smooth and linear response that is shown in below:

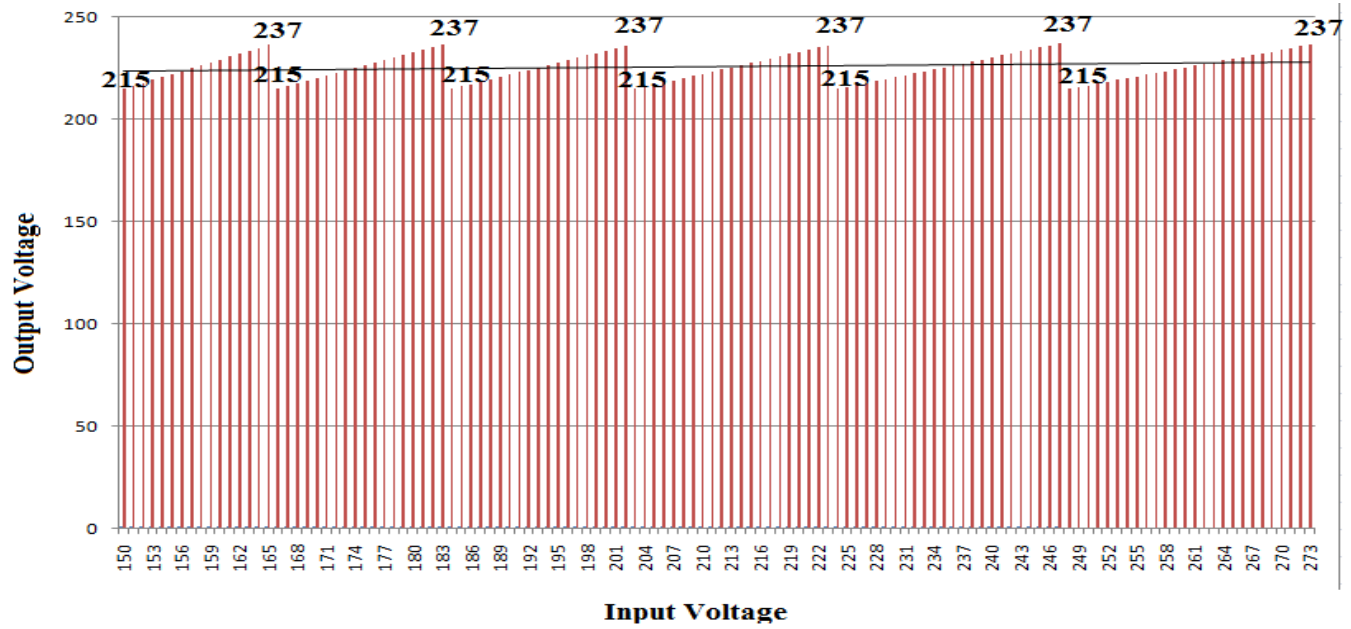

Figure 11. Response Curve; Output Voltage vs. Input Voltage 
It is also maintaining a proper hysteresis with a desired level variation of voltage in switching ON and OFF. Form this 'ON-OFF features of Switch with Input Voltage' graph (Figure12) the hysteresis is evidently defined whenever any switch becomes to switch ON or back to switch OFF [14].

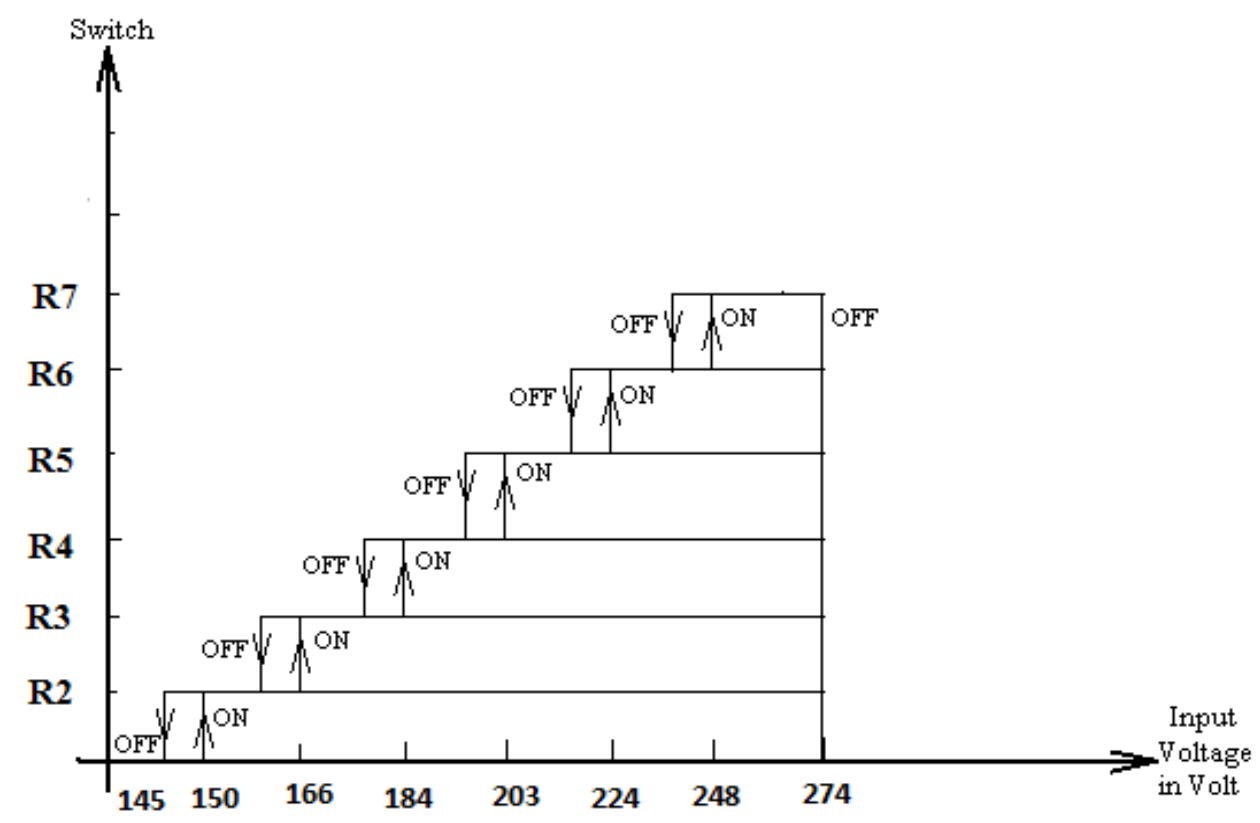

\section{Figure 12. ON-OFF Features of Switch with Input Voltage (Hysteresis Curve)}

\section{Conclusion}

We have used a custom designed transformer and it was costly but other circuit component was cheap enough that the total system costs low or inexpensive. Although, this regulating system is not wide-spreader in our country we hope if it becomes available, the customers will appreciate it. So the proper steps should be taken to encourage the owner of industries to produce this type of regulator system and deliver to the customer at a reasonable price. Here this design ensures to regulate $150 \mathrm{~V}-273 \mathrm{~V}$ AC variation of input to the tolerable range of 215-237 volt AC output. By adding many taps at the secondary side of the auto transformer and relays we can make a new automatic voltage regulator which can regulates input voltage range of $80 \mathrm{VAC}-350 \mathrm{VAC}$ to a stable $220 \mathrm{VAC}$ output voltage.

\section{References}

[1] M. Htay and K. San Win, "Design and Construction of an Automatic Voltage Regulator for Diesel Engine Type Stand-alone Synchronous Generator", PP. 652-658.

[2] C. Valdez, "Voltage stabilizer of Generator output Through Field Current Controlled Using Fuzzy Logic", http://eprints.uthm.edu.my/4326/1/CLARA_VALDEZ.pdf.

[3] P. B. Steciuk and J. R. Redmon, "Voltage sag analysis peaks customer service," IEEE Comput. Appl. Power, vol. 9, (1996) October, pp. 48-51.

[4] S. M. Hietpas, Member, IEEE, and M. Naden, Student Member, IEEE, "Automatic Voltage Regulator Using an AC Voltage-Voltage Converter”, IEEE Transactions on Industry Applications, vol. 36, no. 1, (2000) January-February.

[5] C. Becker, "Proposed Chapter 9 for predicting voltage sags (dips) in revision to IEEE Std. 493, the Gold Book", IEEE Trans. Ind. Applicat., vol. 30, (1994) May-June, pp. 805-821.

[6] M. F. McGranaghan, D. R. Mueller and M. J. Samotyj, "Voltage sags in industrial systems", IEEE Trans. Ind. Applicat., vol. 29, (1993), March-April, pp. 397-403. 
[7] M. H. J. Bollen, "The influence of motor reacceleration on voltage sags", IEEE Trans. Ind. Applicat., vol. 31, (1995), July-August, pp. 667-674.

[8] M. H. J. Bollen, "Characterization of voltage sags experienced by threephase adjustable-speed drives", IEEE Trans. Power Delivery, vol. 12, (1997) October, pp. 1666-1671.

[9] H. G. Sarmiento and E. Estrada, "A voltage sag study in an industry with adjustable speed drives", IEEE Ind. Applicat. Mag., vol. 2, (1996), January-February, pp. 16-19.

[10] C. S. Hoong, S. Taib MIEEE, K. S. Rao and I. Daut, "Development of Automatic Voltage Regulator for Synchronous Generator", National Power \& Energy Conference (PECon) 2004 Proceedings, Kuala Lumpur, Malaysia.

[11] "Specifications and Ratings of Practical AVR", http://www.voltagestabilizer.com and http://www.voltageregulator.com.

[12] "Configuration of Automatic Voltage Regulator", Samsung, Venus, Microtech, Venstab and Silicon, http://www.vener7.com/servo-voltage-stabilizer/.

[13] M. M. Hoque, "Design, implementation and performance study of programmable automatic voltage regulator", Electrical Systems 10-4, (2014), pp. 472-483.

[14] M. M. Hoque and A. I. Mahmod, "An Improved Automatic Voltage Regulation System with Apposite Hysteresis and Immense Precision”, Chittagong University Journal of Science, vol. 33, (2010), pp. 2133.

[15] "Voltage Regulator and Power Supply", http://www.zen22142.zen.co.uk.

[16] G. K. Mithal and Dr. Maneesha Gupta, "Industrial and Power Electronics", $19^{\text {th }}$ Edition, Khanna publishers, (2003), pp. 79-90.

[17] A. Paul Malvino, "Electronic Principles", $6^{\text {th }}$ Edition, Glencoe/Mcgraw-Hill, (1999), pp. 815-826.

[18] J. Millman and C. C. Halkias, "Integrated Electronics, Analog and Digital Circuit and System", Tata McGraw-Hill Edition, (1991), pp. 470-568, 583-585.

[19] W. D. Stevenson, "Elements of power system Analysis", Fourth edition, Mcgraw-Hill College, (1982), pp. 337-341, 354-365.

[20] B. L. Theraja and A. K. Theraja, "A Text Book of electrical Technology", $23^{\text {rd }}$ Edition,_S. Schand \& Company Ltd., New Delhi, India, (2002), pp. 335-338, 1029-1098.

[21] R. L. Boylsted and L. Nashelsky, "Electronic Devices and Circuit theory", 6 ${ }^{\text {th }}$ Edition, Prentice Hall College Div., (1996), pp. 741-748, 773-780. 
International Journal of Advanced Science and Technology Vol.75 (2015) 